\title{
Taxes on unhealthy food and externalities in the parental choice of children's diet
}

\author{
Zarko Kalamov@ | Marco Runkel
}

Faculty of Economics and Management, University of Technology Berlin, Berlin, Germany

\section{Correspondence}

Zarko Kalamov, Faculty of Economics and Management, University of Technology Berlin, Straße des 17. Juni 135, H51, 10623 Berlin, Germany.

Email: zarko.y.kalamov@tu-berlin.de

\begin{abstract}
This study examines whether taxes on unhealthy food are suitable for internalizing intergenerational externalities inflicted by parents when they decide on their children's diet. In an overlapping generations (OLG) model with an imperfectly altruistic parent, the optimal steady-state tax rate on unhealthy food is strictly positive. However, it is only second-best because, in addition to reducing unhealthy consumption by the child, it distorts the parent's unhealthy consumption. Surprisingly, the optimal tax may underinternalize or overinternalize the marginal damage.
\end{abstract}

\section{KEYWORDS}

altruism, fat tax, obesity

JEL CLASSIFICATION

D11; D62; H21; I12

\section{1 | INTRODUCTION}

Noncommunicable diseases (NCDs), such as diabetes, are the major cause of death worldwide, accounting for $70 \%$ of all deaths (WHO, 2017). Unhealthy diets are one of the main risk factors associated with obesity, which, in turn, is a major cause of NCDs. Hence, in its Global Action Plan for the prevention and control of NCDs, the World Health Organization calls for policies to address obesity and explicitly favors taxation of unhealthy food (WHO, 2013). For example, taxes on sugary drinks (soda tax) have been introduced in over 20 countries and in more than half of the U.S. states (Lloyd \& MacLaren, 2019). In the economic literature, taxes on unhealthy food (or sin taxes, in general) are justified based on individuals' lack of self-control (O'Donoghue \& Rabin, 2003; 2006), misperceived health costs (Cremer et al., 2016), negative cost externalities through health insurance (Allcott et al., 2019), and intergenerational transmission of NCDs from parents to their children (Goulão \& Pérez-Barahona, 2014).

Here, we examine whether such taxes are suitable for internalizing intergenerational externalities inflicted by imperfectly altruistic parents when they decide on their children's diet. According to OECD (2017), one out of six children is overweight or obese, implying a higher risk of obesity and related NCDs in adulthood. Parents have a significant impact on their children's diet and are often not perfectly altruistic vis-à-vis their children. The most direct evidence is provided by Bruhin and Winkelmann (2009), who study how children's happiness affects their parents' utility, estimating that only $21 \%$ to $27 \%$ of parents are altruistic. Hence, when choosing their children's diet, parents might not fully consider their children's future health costs and, thus, inflict an intergenerational externality.

We investigate this externality in an overlapping generations (OLG) model of a family in which the parent chooses both its own and its child's diet. Unhealthy food consumption in childhood increases a person's body mass index (BMI) and

This is an open access article under the terms of the Creative Commons Attribution License, which permits use, distribution and reproduction in any medium, provided the original work is properly cited. 
health costs in adulthood and creates habits that raise the marginal utility of unhealthy consumption in adulthood. The parent is imperfectly altruistic and thus considers only a part of the child's future utility and health costs. The government taxes unhealthy food; for simplicity, we refer to this tax as a fat tax. We find that the optimal steady-state tax rate on unhealthy food is indeed strictly positive. However, it is only second-best because, in addition to reducing the food consumption of the child, it distorts the parent's food consumption, which is not associated with an externality. Surprisingly, the optimal tax rate may underinternalize or overinternalize the marginal damage. A tax rate increase in a given period reduces the parent's food consumption in this period, resulting in underinternalization. However, the corresponding reduction in the child's consumption ceteris paribus reduces the BMI in adulthood, which may cause parent consumption in the next period to increase. If this effect is sufficiently large, the second-best tax overinternalizes the marginal damage.

This study is related to the literature on optimal sin taxes. With the notable exception of Goulão and Pérez-Barahona (2014), previous works largely ignore intergenerational externalities between parents and children (see Allcott et al., 2019, for a survey). Goulão and Pérez-Barahona (2014) model a family in which parents choose an unhealthy activity (e.g., food consumption) that influences their health capital, which is later inherited by their children. Parents are imperfectly altruistic and do not consider their children's future utility when deciding on the unhealthy activity. The optimal tax on the unhealthy activity is strictly positive, as in our work. However, in their analysis, the optimal tax is always first-best, because they do not include a second margin, which the tax erroneously distorts. Hence, the important contribution of our study is to identify parents' food consumption as a second margin that renders a tax on unhealthy food second-best.

Our study is also related to the literature on imperfect altruism and intergenerational externalities. See Cremer and Pestieau (2006) and Kopczuk (2013) for surveys of this literature. Except for Goulão and Pérez-Barahona (2014), related studies tend to examine positive externalities that emerge from inheritances when parents are altruistic. Such externalities may call for subsidization of bequests (Cremer \& Pestieau, 2006; Farhi \& Werning, 2010). We contribute to the literature on intergenerational externalities by analyzing the long-term effects of parents' choices related to their children's diets and the implications of these effects for optimal tax policy.

\section{2 | MODEL}

Consider an OLG model of a representative family. ${ }^{1}$ In each period, the family consists of a parent and a child, and each individual lives two periods, childhood and adulthood. In period $t \in\{0,1,2, \ldots\}$, the child's utility from consuming $x_{t}^{c}$ units of unhealthy food and $z_{t}^{c}$ units of healthy food is given by

$$
u_{t}^{c}=z_{t}^{c}+V^{c}\left(x_{t}^{c}\right)
$$

where $V^{c}\left(x_{t}^{c}\right)$ exhibits positive and declining marginal utility from unhealthy foods, such that $V_{x}^{c}\left(x_{t}^{c}\right)>0>V_{x x}^{c}\left(x_{t}^{c}\right) .{ }^{2}$ The child's consumption is chosen by the parent, not the child. In period $t$, the parent receives consumption utility $z_{t}^{p}+V^{p}\left(x_{t}^{p}, s_{t}\right)$ from the consumption of $z_{t}^{p}$ units of healthy food and $x_{t}^{p}$ units of unhealthy food. The utility of unhealthy food consumption is $V^{p}\left(x_{t}^{p}, s_{t}\right)$ and is influenced by habits, defined as

$$
s_{t}=x_{t-1}^{c} \text {. }
$$

Hence, habits equal unhealthy consumption during childhood. In addition, the parent in period $t$ has to bear health costs $C\left(q_{t}\right)$ that are positively correlated with the BMI:

$$
q_{t}=x_{t}^{p}+\gamma x_{t-1}^{c}
$$

The BMI is equal to unhealthy consumption during adulthood, plus a share $\gamma \in[0,1]$ of the unhealthy consumption during childhood. The net utility of the parent in period $t$ is given by

$$
u_{t}^{p}=z_{t}^{p}+V^{p}\left(x_{t}^{p}, s_{t}\right)-C\left(q_{t}\right)
$$

\footnotetext{
${ }^{1}$ All our results hold in a model with family heterogeneity, provided there is a positive mass of families with imperfectly altruistic parents. The optimal tax then turns out to be third-best.

${ }^{2}$ Throughout the paper, uppercase letters denote functions and subscripts attached to them indicate (partial) derivatives, for example, $V_{x}^{c}\left(x_{t}^{c}\right):=$ $d V^{c}\left(x_{t}^{c}\right) / d x_{t}^{c}, V_{x x}^{c}\left(x_{t}^{c}\right):=d^{2} V^{c}\left(x_{t}^{c}\right) / d\left(x_{t}^{c}\right)^{2}$.
} 
The utility function $V^{p}$ exhibits positive and declining marginal utility from unhealthy food; that is, $V_{x}^{p}\left(x_{t}^{p}, s_{t}\right)>0>$ $V_{x x}^{p}\left(x_{t}^{p}, s_{t}\right)$. The marginal utility of habits is assumed to be negative and declining; thus, $V_{s}^{p}\left(x_{t}^{p}, s_{t}\right)<0$ and $V_{s s}^{p}\left(x_{t}^{p}, s_{t}\right)<0$. Moreover, the utility function satisfies $V_{x s}^{p}\left(x_{t}^{p}, s_{t}\right)>0$. Hence, the parent's marginal utility from unhealthy food consumption is increasing in past consumption and, ceteris paribus, incentivizes the adult to consume more when more was eaten during childhood. ${ }^{3}$ Finally, the marginal health costs are positive and increasing; that is, $C_{q}\left(q_{t}\right)>0$ and $C_{q q}\left(q_{t}\right) \geq 0$.

The long-term utility of the parent in period $t$ is equal to

$$
W_{t}=u_{t}^{c}+u_{t}^{p}+\alpha W_{t+1},
$$

where $W_{t+1}$ is the long-term utility of a child born in period $t$ when it becomes a parent in period $t+1$. The weight $\alpha \in[0,1]$ determines the degree of (intergenerational) altruism. If $\alpha=1$, the parent fully considers the long-term utility of its child and is perfectly altruistic. For $\alpha=0$, the parent is nonaltruistic. If $\alpha \in(0,1)$, the parent is imperfectly altruistic. Lastly, the family's budget constraint in period $t$ is given by

$$
z_{t}^{p}+z_{t}^{c}+\left(1+\tau_{t}\right)\left(x_{t}^{p}+x_{t}^{c}\right)=e+\ell_{t},
$$

where $e$ is a given income, $\ell_{t}$ represents a lump sum transfer received from the government, and $\tau_{t}$ is the tax rate on unhealthy food consumption (i.e., the fat tax). All producer prices are normalized to unity.

\section{3 | CONSUMPTION CHOICE OF THE PARENT}

In period $t$, the parent chooses its own consumption, $z_{t}^{p}$ and $x_{t}^{p}$, and the child's consumption, $z_{t}^{c}$ and $x_{t}^{c}$, in order to maximize its utility (5), subject to (1)-(4) and the budget constraint (6) for period $t$, and all periods thereafter. In so doing, it takes as given habits $s_{t}=x_{t-1}^{c}{ }^{4}$ To simplify the model's exposition and interpretation, define $U\left(x_{t}^{p}, s_{t}\right):=V^{p}\left(x_{t}^{p}, s_{t}\right)-C\left(x_{t}^{p}+\gamma s_{t}\right)$ as the net utility of a given lifetime unhealthy consumption allocation $\left(s_{t}, x_{t}^{p}\right)$ of the parent in period $t$. The first-order conditions are (see Online Appendix A)

$$
\begin{gathered}
U_{x}\left(x_{t}^{p *}, x_{t-1}^{c *}\right)-1-\tau_{t}=0, \\
V_{x}^{c}\left(x_{t}^{c *}\right)-1-\tau_{t}+\alpha U_{s}\left(x_{t+1}^{p *}, x_{t}^{c *}\right)=0,
\end{gathered}
$$

where the asterisk indicates the decentralized solution. According to (7), the parent chooses its own unhealthy consumption such that the net marginal utility, $U_{x}=V_{x}^{p}-C_{q}$, is equal to the marginal monetary cost $1+\tau_{t}$. Equation (8) states that the parent sets the child's unhealthy consumption such that the marginal utility, $V_{x}^{c}$, is equal to the perceived long-term marginal costs, $-\alpha U_{s}=-\alpha\left(V_{s}^{p}-\gamma C_{q}\right)>0$, plus the marginal monetary cost, $1+\tau_{t}$. Hence, in the case of a zero tax, $\tau_{t}=0$, the parent considers only part of the child's future costs, creating an externality reflected by the share of marginal costs that it ignores, that is, $-(1-\alpha) U_{s}$.

Lagging the equations in (7) by one period yields

$$
U_{x}\left(x_{t+1}^{p *}, x_{t}^{c *}\right)-1-\tau_{t+1}=0
$$

For each period $t \in\{0,1,2, \ldots\}$, (8) and (9) form a system of equations that determines child consumption in period $t$ and parent consumption in period $t+1$ as functions of the tax rates in period $t$ and period $t+1$. Formally, we obtain $x_{t}^{c *}=X^{c}\left(\tau_{t}, \tau_{t+1}\right)$ and $x_{t+1}^{p *}=X^{p}\left(\tau_{t}, \tau_{t+1}\right) .{ }^{5}$ Differentiating (8) and (9) gives the comparative static results

$$
\frac{\partial x_{t+1}^{p *}}{\partial \tau_{t+1}}=\frac{V_{x x}^{c}+\alpha U_{s s}}{\Delta}<0, \quad \frac{\partial x_{t}^{c *}}{\partial \tau_{t}}=\frac{U_{x x}}{\Delta}<0,
$$

\footnotetext{
${ }^{3}$ These properties of the utility function with respect to habits are satisfied for the most commonly used specifications of habits, namely, the subtractive habit specification $V^{p}(x, s)=v(x-\theta s)$, with $v^{\prime}>0>v^{\prime \prime}$ and $\theta \in(0,1)$ (see Lahiri \& Puhakka, 1998, and Carroll, 2000), and the multiplicative habit specification $V^{p}(x, s)=v\left(x / s^{\theta}\right)$, with $v^{\prime}>0>v^{\prime \prime}$ and $\theta \in(0,1)$ pioneered by Abel (1990).

${ }^{4}$ Note that the quasi-linearity of the preferences means that the utility-maximizing choices determine only $x_{t}^{p}, x_{t}^{c}$, and $z_{t}^{c}+z_{t}^{p}$. The distribution of healthy consumption between the parent and the child is undetermined, because it does not affect the family utility.

${ }^{5}$ In Period 0, we obtain from (7) the additional condition $U_{x}\left(x_{0}^{p *}, x_{-1}^{c}\right)-1-\tau_{0}=0$, where $x_{-1}^{c}$ is predetermined. This condition yields $x_{0}^{p *}$ as a function of $\tau_{0}$. Because we subsequently focus on the steady-state only, we can safely ignore this condition from the initial period.
} 


$$
\frac{\partial x_{t+1}^{p *}}{\partial \tau_{t}}=-\frac{U_{x s}}{\Delta} \gtreqless 0, \quad \frac{\partial x_{t}^{c *}}{\partial \tau_{t+1}}=-\frac{\alpha U_{x s}}{\Delta} \gtreqless 0,
$$

where $\Delta:=U_{x x} V_{x x}^{c}+\alpha\left[U_{x x} U_{s s}-U_{x s}^{2}\right]>0$, for stability reasons. An increase in the tax rate in a given period raises the marginal costs of unhealthy consumption, thus reducing child and parent consumption in that period, as shown in (10). The decrease in period $t$ child consumption, following an increase in the period $t$ tax rate, has two opposing effects on parent consumption in $t+1$, characterized by $U_{x s}=V_{x s}^{p}-\gamma C_{q q}$. On the one hand, it reduces the BMI of the parent in $t+1$. Therefore, the parent in $t+1$ may increase its consumption during adulthood (owing to $\gamma C_{q q}>0$ ). On the other hand, the reduction in child consumption in $t$ weakens the habits in $t+1$, giving the parent in $t+1$ an incentive to reduce its own consumption (owing to $-V_{x s}^{p}<0$ ). Combining these effects, the first expression in (11) shows that the impact of the period $t$ tax rate on parent consumption in $t+1$ is ambiguous. Similarly, the reduction in parent consumption in $t+1$, following an increase in the period $t+1$ tax rate, reduces the long-term marginal costs perceived by the parent in $t$ by lowering the marginal health costs and increases the long-term marginal costs of stronger habits. Owing to $\alpha \gamma C_{q q}>0$ and $-\alpha V_{x s}^{p}<0$, these changes in the perceived marginal costs translate into opposing effects on child consumption in $t$. Therefore, the parent may increase or decrease child consumption in $t$ if the period $t+1$ tax rate goes up, as shown in the second part of (11). Thus, we can define $U_{x s}$ as the degree of net addictiveness of unhealthy food, where a good is addictive in net terms if child consumption raises the net marginal utility during adulthood. The intertemporal tax effects in (11) are negative if unhealthy food is addictive in net terms, and positive otherwise. ${ }^{6}$

Note, furthermore, that habit formation is not necessary for the existence of an externality in the decentralized solution. Even when $V_{s}^{p}=0$, imperfect altruism creates an externality because of the long-term health costs of unhealthy consumption during childhood: $-(1-\alpha) U_{s}=(1-\alpha) \gamma C_{q}>0$. In the special case $\alpha=0$, the parent is nonaltruistic and fully ignores the long-term effects of an unhealthy child's diet. In contrast, when $\alpha=1$, the parent is fully altruistic, and the decentralized solution is optimal.

\section{4 | OPTIMAL POLICY}

The present value of social welfare can be expressed as $\hat{W}_{0}=\sum_{t=0}^{\infty}\left(u_{t}^{p}+u_{t}^{c}\right)$. Inserting (1)-(4), (6), and the public budget constraint $\ell_{t}=\tau_{t}\left(x_{t}^{p *}+x_{t}^{c *}\right)$ yields

$$
\hat{W}_{0}=\sum_{t=0}^{\infty}\left[e-x_{t}^{p *}-x_{t}^{c *}+U\left(x_{t}^{p *}, x_{t-1}^{c *}\right)+V^{c}\left(x_{t}^{c *}\right)\right]
$$

The optimal policy maximizes this welfare function, taking into account the comparative static effects (10) and (11). In determining the optimal fat tax rate in period $t$, we must consider the effects on period $t$ child consumption $x_{t}^{c *}=$ $X^{c}\left(\tau_{t}, \tau_{t+1}\right)$ and period $t+1$ parent consumption $x_{t+1}^{p *}=X^{p}\left(\tau_{t}, \tau_{t+1}\right)$. Moreover, the period $t$ tax rate influences period $t-1$ child consumption $x_{t-1}^{c *}=X^{c}\left(\tau_{t-1}, \tau_{t}\right)$ and period $t$ parent consumption $x_{t}^{p *}=X^{p}\left(\tau_{t-1}, \tau_{t}\right)$. Differentiating (12) with respect to $\tau_{t}$ and taking into account these effects and (8) and (9), we obtain for $t \in\{1,2, \ldots\},{ }^{7}$

$$
\begin{aligned}
\frac{\partial \hat{W}_{0}}{\partial \tau_{t}}= & {\left[\tau_{t-1}+(1-\alpha) U_{s}\left(x_{t}^{p *}, x_{t-1}^{c *}\right)\right] \frac{\partial x_{t-1}^{c *}}{\partial \tau_{t}}+\tau_{t} \frac{\partial x_{t}^{p *}}{\partial \tau_{t}} } \\
& +\left[\tau_{t}+(1-\alpha) U_{s}\left(x_{t+1}^{p *}, x_{t}^{c *}\right)\right] \frac{\partial x_{t}^{c *}}{\partial \tau_{t}}+\tau_{t+1} \frac{\partial x_{t+1}^{p *}}{\partial \tau_{t}}=0 .
\end{aligned}
$$

${ }^{6}$ The authors thank an anonymous referee for providing this interpretation.

${ }^{7}$ In $t=0$, the first term in (13) vanishes because $x_{-1}^{c}$ is predetermined. We can ignore this difference between $t=0$ and all other periods because we subsequently focus on the steady state only. 
As in Goulão and Pérez-Barahona (2014), we focus on the properties of the optimal tax in the steady state, with $\tau_{t-1}=$ $\tau_{t}=\tau_{t+1}=: \tau^{*}$. Inserting into (13) and solving gives

$$
\tau^{*}=-(1-\alpha) U_{s} \Omega \quad \text { with } \quad \Omega:=\left(1+\frac{\frac{\partial x_{t}^{p *}}{\partial \tau_{t}}+\frac{\partial x_{t+1}^{p *}}{\partial \tau_{t}}}{\frac{\partial x_{t-1}^{c *}}{\partial \tau_{t}}+\frac{\partial x_{t}^{c *}}{\partial \tau_{t}}}\right)^{-1} \text {. }
$$

The government would exactly internalize the externality if the tax is equal to the part of the marginal long-term costs of unhealthy consumption not considered by the parent, that is, $-(1-\alpha) U_{s}$. If the tax is lower (higher) than this level, the externality is underinternalized (overinternalized). Using expression (14), Online Appendix B proves the following proposition.

Proposition 1. For any $\alpha \in[0,1)$, the optimal steady-state fat tax rate $\tau^{*}$ is strictly positive. In general, however, it deviates from the first-best policy and is only second-best. We obtain underinternalization (overinternalization) iff

$$
V_{x x}^{c}+\alpha U_{s s}-U_{x s}<(>) 0
$$

Increasing the fat tax reduces unhealthy child consumption. This effect is intended because child consumption creates an externality. At the same time, the increase in the fat tax changes parent consumption, which is not intended because it does not cause an externality. However, this latter effect is of second order, implying that the optimal tax is strictly positive, as stated in the first part of the proposition.

The unintended distortion of parent consumption explains why the optimal tax is not first-best, as stated in the second part of the proposition. A tax rate increase in a given period reduces parent consumption in this period. It may seem that the optimal tax rate has to underinternalize the external marginal costs, $-(1-\alpha) U_{s}$, in order to mitigate the unintended reduction in parent consumption. However, in addition to the intra temporal effect, there is an inter temporal effect on parent consumption in the next period, which may lead to overinternalization. Here, the intratemporal effect is reflected by $\partial x_{t+1}^{p^{*}} / \partial \tau_{t+1}$ in (10), and $\partial x_{t+1}^{p^{*}} / \partial \tau_{t}$ in (11) gives the intertemporal effect, where all expressions are evaluated at the steady state. The intratemporal effect is negative, whereas the intertemporal effect is ambiguous; recall that it may be positive because the decrease in consumption during childhood and the corresponding decrease in BMI in adulthood, ceteris paribus, induces the parent to eat more during adulthood. If the intertemporal effect is positive and larger, in absolute terms, than the intratemporal effect, then the fat tax has an unintended positive effect on the steady-state consumption of the parent; thus, the optimal fat tax overinternalizes the external costs. In terms of the model primitives $V^{p}, V^{c}$, and $C$, the conditions for underinternalization and overinternalization are given in (15). Furthermore, if unhealthy food is net addictive $\left(U_{x s}>0\right)$, the optimal tax underinternalizes the externality, because (15) is negative in this case. However, if unhealthy food is not addictive in net terms $\left(U_{x s}<0\right)$, the optimal tax may be larger than the externality. ${ }^{8}$

\section{ALTERNATIVE SOCIAL WELFARE FUNCTION}

In the previous analysis, we defined social welfare as the sum of the parent's short-term utility and the child's long-term utility and excluded the parent's altruistic preferences. This definition is supported by Hammond (1987) and Harsanyi (1995), among others, because including the parent's altruistic preferences would lead to a "double-counting" of the child's utility. However, other authors take a welfarist approach and (partially) "double-count" the child's utility; see Kaplow (1998), Farhi and Werning (2010), Brunner and Pech (2012a), Brunner and Pech (2012b), and Boadway and Cuff (2015).

Following Brunner and Pech (2012b) and Boadway and Cuff (2015), we assume the government puts a weight $\delta \in[0,1]$ on the parent's long-term utility in the welfare function. Thus, social welfare in period $t$ is

$$
\hat{W}_{t}=u_{t}^{p}+u_{t}^{c}+\delta \alpha \hat{W}_{t+1}+\hat{W}_{t+1}
$$

${ }^{8}$ Overinternalization is obtained, for example, if parents are nonaltruistic $(\alpha=0)$ and habits are absent $\left(V_{x s}^{p}=V_{s s}^{p}=0\right)$. For $V^{c}(x)=a x-b x^{2} / 2$ and $C(q)=c q^{2}$, overinternalization occurs if $\gamma c>b$. 
Iterating and evaluating at $t=0$ yields the present value of social welfare,

$$
\hat{W}_{0}=\sum_{t=0}^{\infty}(1+\delta \alpha)^{t}\left(u_{t}^{p}+u_{t}^{c}\right)
$$

If $\delta=0$, there is no "double-counting" and (17) coincides with (12). If $\delta=1$, the other extreme case of full "double-counting" emerges. However, the externality associated with the choice of the child's diet increases with $\delta$. Hence, in the case $\delta>0$, unhealthy food should be taxed even if $\alpha=1$, that is, even if the parents are fully altruistic. Thus, adopting a welfarist approach strengthens the case for a positive fat tax.

\section{6 | CONCLUSION}

We develop an OLG model to analyze imperfect altruism within the family as a rationale for fat taxes. We show that imperfect altruism is an argument for taxation of unhealthy food; however, the optimal tax rate is only second-best and may underinternalize or overinternalize the intergenerational externality. The latter result relies on our implicit assumption of a uniform tax on parent and child consumption. If taxation can discriminate between parent and child consumption, a zero tax on the former and a tax equal to the marginal externality on the latter would be sufficient. However, in practice, it is often difficult or even impossible to tax parent and child food consumption differently. An example of uniform taxation is the soda tax, the tax base of which, sugary drinks, is consumed by both children and adults.

However, discrimination may be possible if we consider further policy instruments and determinants of obesity. For instance, the proceeds of the fat tax could be used to finance policies aimed at children, instead of being returned to adults through lump-sum transfers. One such policy is implemented in the United Kingdom, where proceeds from the soda tax are used to finance schools' sport provision (HCL, 2017). A further extension may consider other types of unhealthy behavior (e.g., smoking and drinking alcohol), where early habits influence adult behavior. These extensions are left for future research.

\section{ORCID}

Zarko Kalamov (iD https://orcid.org/0000-0002-1016-3415

Marco Runkel (D) https://orcid.org/0000-0002-9306-1974

\section{REFERENCES}

Abel, A. (1990). Asset prices under habit formation and catching up with the Joneses. American Economic Review, 80(2), 38-42.

Allcott, H., Lockwood, B., \& Taubinsky, D. (2019). Should we tax sugar-sweetened beverages? An overview of theory and evidence. Journal of Economic Pespectives, forthcoming.

Boadway, R., \& Cuff, K. (2015). Tax treatment of bequests when donor benefits are discounted. International Tax and Public Finance, 22(4), 604-634.

Bruhin, A., \& Winkelmann, R. (2009). Happiness functions with preference interdependence and heterogeneity: The case of altruism within the family. Journal of Population Economics, 22(4), 1063-1080.

Brunner, J. K., \& Pech, S. (2012a). Optimal taxation of bequests in a model with initial wealth. Scandinavian Journal of Economics, 114(4), 1368-1392.

Brunner, J. K., \& Pech, S. (2012b). Optimal taxation of wealth transfers when bequests are motivated by joy of giving. The B.E. Journal of Economic Analysis \& Policy, 12(1), 1-22.

Carroll, C. (2000). Solving consumption models with multiplicative habits. Economics Letters, 68(1), 67-77.

Cremer, H., Goulão, C., \& Roeder, K. (2016). Earmarking and the political support of fat taxes. Journal of Health Economics, 50(C), $258-267$.

Cremer, H., \& Pestieau, P. (2006). Wealth transfer taxation: A survey of the theoretical literature, (1st ed.). In Kolm, S., \& Ythier, J. M. (Eds.), Handbook of the Economics of Giving, Altruism and Reciprocity, chapter 16, Vol. 1: Elsevier, pp. 1107-1134.

Farhi, E., \& Werning, I. (2010). Progressive estate taxation. The Quarterly Journal of Economics, 125(2), 635-673.

Goulão, C., \& Pérez-Barahona, A. (2014). Intergenerational transmission of noncommunicable chronic diseases. Journal of Public Economic Theory, 16(3), 467-490.

Hammond, P. J. (1987). Altruism. In Eatwell, J., Milgate, M., \& Newman, P. (Eds.), The new Palgrave: A dictionary of economics: Palgrave Macmillan, pp. 85-87.

HCL (2017). Funding from the soft drinks industry levy for sport in schools. (CDP 2017/0006): House of Commons Library.

Harsanyi, J. C. (1995). A theory of prudential values and a rule utilitarian theory of morality. Social Choice and Welfare, 12(4), 319-333.

Kaplow, L. (1998). Tax policy and gifts. The American Economic Review, Papers and Proceedings, 88(2), 283-288. 
Kopczuk, W. (2013). Chapter 6-Taxation of intergenerational transfers and wealth. In Auerbach, AlanJ., Chetty, Raj, Feldstein, Martin, \& Saez, Emmanuel (Eds.), Handbook of Public Economics, Vol. 5, pp. 329-390.

Lahiri, A., \& Puhakka, M. (1998). Habit persistence in overlapping generations economies under pure exchange. Journal of Economic Theory, $78(1), 176-186$

Lloyd, P., \& MacLaren, D. (2019). Should we tax sugar and if so how. Australian Economic Review, 52(1), 19-40.

O'Donoghue, T., \& Rabin, M. (2003). Studying optimal paternalism, illustrated by a model of sin taxes. American Economic Review, 93(2), 186-191.

O'Donoghue, T., \& Rabin, M. (2006). Optimal sin taxes. Journal of Public Economics, 90(10-11), 1825-1849.

OECD (2017). Obesity update https://www.oecd.org/els/health-systems/Obesity-Update-2017.pdf

WHO (2013). Global action plan for the prevention and control of noncommunicable diseases 2013-2020.

WHO (2017). Noncommunicable diseases progress monitor.

\section{SUPPORTING INFORMATION}

Additional supporting information may be found online in the Supporting Information section at the end of the article.

How to cite this article: Kalamov Z, Runkel M. Taxes on unhealthy food and externalities in the parental choice of children's diet. Health Economics. 2020;29:938-944. https://doi.org/10.1002/hec.4024 